\title{
Pathologic stage I non-small cell lung cancer with high levels of preoperative serum carcinoembryonic antigen: Clinicopathologic characteristics and prognosis
}

Haruhisa Matsuguma, MD, ${ }^{\text {a }}$ Rie Nakahara, MD, ${ }^{\text {a }}$ Seiji Igarashi, MD, ${ }^{b}$ Yoshinori Ishikawa, MD, ${ }^{\text {a,d }}$ Haruko Suzuki, MD, ${ }^{\text {a,d }}$ Naoto Miyazawa, MD, ${ }^{a}$ Satoshi Honjo, MD, ${ }^{\mathrm{c}, \mathrm{e}}$ and Kohei Yokoi, MD ${ }^{\mathrm{a}, \mathrm{d}}$

Earn CME credits at http:// cme.ctsnetjournals.org
From the Divisions of Thoracic Surgery, Pathology, ${ }^{\mathrm{b}}$ and Epidemiology, ${ }^{\mathrm{c}}$ Tochigi Cancer Center, Utsunomiya, Japan; Division of Thoracic Surgery, ${ }^{\mathrm{d}}$ Nagoya University Graduate School of Medicine, Nagoya, Japan; and Pediatrics Unit, ${ }^{\mathrm{e}}$ Oomuta National Hospital, National Hospital Organization, Oomuta, Japan.

Received for publication April 16, 2007; revisions received Aug 24, 2007; accepted for publication Sept 11, 2007.

Address for reprints: Haruhisa Matsuguma, MD, Division of Thoracic Surgery, Tochigi Cancer Center, 4-9-13 Yohnan, Utsunomiya, Tochigi 320-0834, Japan (E-mail: hmatsugu@tcc.pref.tochigi.jp).

J Thorac Cardiovasc Surg 2008;135:44-9 $0022-5223 / \$ 34.00$

Copyright $(\underset{2008}{ } 20 \mathrm{by}$ The American Association for Thoracic Surgery

doi:10.1016/j.jtcvs.2007.09.032
Objective: Surgery alone remains the standard therapy for patients with stage I nonsmall cell lung cancer. Although the preoperative serum level of carcinoembryonic antigen has been shown to be an independent prognostic factor, it has not yet been included in the staging system and does not alter the treatment strategy, especially in the selection of patients for adjuvant chemotherapy.

Methods: From 1986 to 2003, preoperative and postoperative serum carcinoembryonic antigen levels were measured in 455 patients with completely resected pathologic stage I non-small cell lung cancer. We compared the clinicopathologic characteristics and outcomes among patients who had preoperative serum carcinoembryonic antigen levels within the normal range ( $\mathrm{N}$ group, $\mathrm{n}=323$ ), patients who had high carcinoembryonic antigen levels before surgery but normal levels after surgery (HN group, $\mathrm{n}=112$ ), and patients who had high carcinoembryonic antigen levels before and after surgery (HH group, $\mathrm{n}=20$ ).

Results: The significant characteristics of the HN group included the male sex, greater age, smoking, squamous cell histology, T2 status, lymphatic invasion, vascular invasion, and pleural invasion. Adenocarcinomas in patients of the $\mathrm{HN}$ group were more likely to be moderately to poorly differentiated. The 5 -year survivals in the $\mathrm{HN}$ and $\mathrm{HH}$ groups were significantly lower $(56.2 \%$ and $43.1 \%$, respectively) than those in the $\mathrm{N}$ group $(85.9 \%)$. Multivariate analysis revealed that greater age, non-adenocarcinoma histology, pleural invasion, and the carcinoembryonic antigen in the HN and $\mathrm{HH}$ groups were independent prognostic factors.

Conclusion: Patients with resected pathologic stage I non-small cell lung cancer and high preoperative serum carcinoembryonic antigen levels are a subgroup with a distinctly poor prognosis who display smoking-related clinicopathologic characteristics.

$\mathrm{R}$ ecent randomized controlled trials have shown a survival benefit from adjuvant chemotherapy in patients with stage II or more advanced non-small cell lung cancer (NSCLC) ${ }^{1-3}$ whereas surgery alone remains the standard therapy for patients with stage I disease. However, it has been thought that there is a subgroup of patients with stage I NSCLC who have a poor prognosis but for whom adjuvant chemotherapy can be as effective as in patients with more advanced disease. ${ }^{4}$ Therefore, identification of this subgroup is clinically important.

Many prognostic indicators, including tumor markers, ${ }^{5,6}$ pathologic factors, ${ }^{7-10}$ and genetic change, ${ }^{4}$ have been reported for patients with stage I NSCLC. Among these indicators, tumor markers are simple to measure and can be judged as abnormal clearly and consistently by different institutions if a cutoff value is set.

Of the tumor markers tested as prognostic factors for NSCLC, carcinoembryonic antigen (CEA) has been demonstrated by several studies to be an independent prognostic factor for patients with clinical stage I NSCLC. ${ }^{5,6}$ Preoperative CEA values, however, have not yet been included in the staging system and do not alter the 


\section{Abbreviations and Acronyms \\ BVI = blood vessel invasion \\ CEA $=$ carcinoembryonic antigen \\ NSCLC $=$ non-small cell lung cancer \\ VPI $=$ visceral pleural invasion}

treatment strategy, especially in selecting patients for adjuvant chemotherapy, either in practice or in clinical trials.

We believe that elucidating the clinicopathologic characteristics of patients with stage I NSCLC showing high preoperative values of CEA will increase the understanding of this poor prognostic subgroup who require treatment strategies distinct from those for patients with stage I NSCLC.

We have two reasons for believing that high CEA values are associated with a poor prognosis in patients with clinical stage I NSCLC. One reason is that high preoperative CEA values are associated with a more advanced pathologic stage after surgery. ${ }^{5,11}$ Another reason is that high CEA values are directly related to the tumor's aggressive nature. To clarify the later point, we compared the clinicopathologic characteristics and outcomes of patients who had pathologic stage I NSCLC and normal preoperative CEA values with those of patients who had high CEA values before surgery but normal levels after resection, for whom the primary tumor is thought to be responsible for the high preoperative CEA values. In addition, we analyzed patients who had high CEA values both before and after resection, because we anticipated that this subgroup would have the lowest survival.

\section{Materials and Methods}

From October of 1986 to May of 2003, we measured serum CEA levels before and after resection in 455 consecutive patients with pathologic stage I disease who underwent complete resection for primary NSCLC. Institutional review board approval was obtained for collecting the data in a secure database and reporting the results of analyses. Patients who had received preoperative chemotherapy or radiotherapy were excluded. Stage was determined according to the international TNM staging system. ${ }^{12}$ The histologic type of tumor was determined using the World Health Organization classification. ${ }^{13}$

There were 277 male and 178 female patients, with a mean age of 65 years (range, $35-85$ years). The histologic types were adenocarcinoma ( $\mathrm{n}=313)$, squamous cell carcinoma $(\mathrm{n}=112)$, and others $(\mathrm{n}=30)$. Primary tumors were classified as T1 in 301 patients and as T2 in 154 patients. Surgical treatment was performed as follows: pneumonectomy in 2 patients, lobectomy in 398 patients, segmentectomy in 32 patients, and partial resection in 23 patients. Systematic nodal dissection was performed in 386 patients, whereas sampling or no resection of mediastinal or hilar lymph node was performed in 69 patients for whom no node metastasis was clinically suspected.

Serum CEA levels were measured within a 1-month period before surgery and again 1 to 3 months after surgery. An enzyme immunoassay method was used to measure the serum CEA level.
The cutoff value of CEA was $5.0 \mathrm{ng} / \mathrm{mL}$ according to the manufacturer.

We placed patients in the $\mathrm{N}$ group if the preoperative CEA value was within the normal range, in the HN group if the CEA value was high before surgery but was normal after surgery, and in the $\mathrm{HH}$ group if the CEA value was high both before and after surgery.

Four-micrometer-thick sections, including the largest piece cut from the surface of the tumor in each case, were stained with hematoxylin-eosin and elastica van Gieson stains and examined by means of light microscopy. Intratumoral blood vessel invasion (BVI) was determined by means of the identification of tumor cells in blood vessels. Lymphatic invasion was also morphologically distinguished from vascular invasion. Visceral pleural invasion (VPI) was judged to be present if tumor cells had invaded across the visceral pleural elastic layer.

The patients were scheduled for checkups, chest radiography, and measurement of tumor marker serum levels every 1 to 3 months for 2 years after the operation and every 6 months thereafter. All patients except 29 were followed up until death or the last day of follow-up (December 31, 2005). Of the 29 patients not followed up, 24 completed their follow-up after the 5-year anniversary of surgery. The average length of follow-up for surviving patients was 90 months (range, 32-236 months).

We investigated the association of the CEA group with clinicopathologic findings and survival. The chi-square or Fisher exact test was used to compare several clinical and pathologic factors. Survival was measured from the date of surgery until death from any cause. Survival curves were calculated with the Kaplan-Meier method, and differences in survival were determined by the logrank test. Multivariate analysis of several prognostic factors was performed with Cox's proportional hazards regression model. Statistical calculations were conducted with Stat View 5.0 (SAS Institute Inc, Cary, NC).

\section{Results}

Of 455 patients with pathologic stage I NSCLC, $323(70.9 \%)$ were in the $\mathrm{N}$ group, $112(24.6 \%)$ were in the $\mathrm{HN}$ group, and $20(4.3 \%)$ were in the HH group. The patients' clinical and pathologic characteristics according to the CEA group are shown in Table 1 . The HN group was significantly related to the male sex $(P=.0014)$, greater age $(P=<.0001)$, smoking $(P<.0001)$, squamous cell histology $(P=.016)$, and T2 status $(P<.0001)$ when compared with the $\mathrm{N}$ group. Adenocarcinomas in patients of the $\mathrm{HN}$ group were more likely to be moderately or poorly differentiated $(P<$ .0001). On the other hand, among squamous cell tumors, the CEA group was not significantly correlated with the degree of differentiation. The HN group also showed significantly higher rates of BVI and VPI.

Figure 1, $A$ shows survival curves according to the CEA group. Five- and 10-year survivals were significantly lower in the $\mathrm{HN}$ group $(56.2 \%$ and $34.1 \%)$ and $\mathrm{HH}$ group $(43.1 \%$ and $24.6 \%$ ) than in the $\mathrm{N}$ group $(85.9 \%$ and $72.3 \% ; P=$ $.0001)$. Figure $1, B$ shows cancer-specific survival curves according to the CEA group. Survivals in the HH group and the $\mathrm{HN}$ group were significantly lower than that in the $\mathrm{N}$ group. 
TABLE 1. Clinicopathologic characteristics of patients with pathologic stage I non-small cell lung cancer $(n=455)$

\begin{tabular}{|c|c|c|c|c|c|}
\hline Characteristics & Total & $\begin{array}{c}\mathbf{N} \\
\text { Group }\end{array}$ & $\begin{array}{c}\text { HN } \\
\text { Group }\end{array}$ & $\begin{array}{c}\text { HH } \\
\text { Group }\end{array}$ & $\begin{array}{c}P \\
\text { value } \ddagger\end{array}$ \\
\hline \multicolumn{6}{|l|}{ Sex } \\
\hline Male & 279 & 181 & 82 & 14 & .0014 \\
\hline Female & 178 & 142 & 30 & 6 & \\
\hline \multicolumn{6}{|l|}{ Age (y) } \\
\hline$<67 \mathrm{y}$ & 220 & 180 & 36 & 4 & $<.0001$ \\
\hline$\geq 67$ y & 235 & 143 & 76 & 16 & \\
\hline \multicolumn{6}{|l|}{ Smoking history } \\
\hline Never smoker & 160 & 137 & 21 & 2 & $<.0001$ \\
\hline Former smoker & 114 & 81 & 31 & 2 & \\
\hline Current smoker & 181 & 105 & 60 & 16 & \\
\hline \multicolumn{6}{|l|}{ Histology } \\
\hline Adenocarcinoma & 313 & 237 & 67 & 9 & $.0166^{*}$ \\
\hline Well differentiated & 143 & 125 & 17 & 1 & $<.0001$ \\
\hline Moderately differentiated & 143 & 100 & 36 & 7 & \\
\hline Poorly differentiated & 27 & 12 & 14 & 1 & \\
\hline Squamous & 112 & 67 & 38 & 7 & \\
\hline Well differentiated & 8 & 6 & 2 & 0 & $.5771 \dagger$ \\
\hline Moderately differentiated & 89 & 53 & 30 & 6 & \\
\hline Poorly differentiated & 15 & 8 & 6 & 1 & \\
\hline Other & 30 & 19 & 7 & 4 & \\
\hline \multicolumn{6}{|l|}{ Pathologic tumor status } \\
\hline $\mathrm{T} 1$ & 301 & 233 & 51 & 17 & $<.0001$ \\
\hline T2 & 154 & 90 & 61 & 3 & \\
\hline \multicolumn{6}{|l|}{ Lymphatic invasion } \\
\hline No & 386 & 280 & 90 & 16 & .1054 \\
\hline Yes & 69 & 43 & 22 & 4 & \\
\hline \multicolumn{6}{|l|}{ Vascular invasion } \\
\hline No & 310 & 238 & 62 & 10 & .0003 \\
\hline Yes & 145 & 85 & 50 & 10 & \\
\hline \multicolumn{6}{|l|}{ Pleural invasion } \\
\hline No & 356 & 270 & 73 & 13 & $<.0001$ \\
\hline Yes & 99 & 53 & 39 & 7 & \\
\hline \multicolumn{6}{|l|}{ Recurrence } \\
\hline No & 367 & 279 & 77 & 11 & .0008 \\
\hline Yes & 80 & 43 & 29 & 8 & \\
\hline Unknown & 8 & 1 & 6 & 1 & \\
\hline
\end{tabular}

*Comparison among adenocarcinoma, squamous, and other histologic types.

$\dagger$ †Comparison of poorly differentiated with moderately and well-differentiated NSCLC.

$\ddagger P$ value for the chi-square test for the association between the $\mathrm{N}$ group and the HN group and clinicopathologic characteristics.

Figure 2 shows survival curves and cancer-specific survival curves according to the CEA group and pathologic $\mathrm{T}$ factor. Among patients with pathologic stage IA NSCLC, those in the $\mathrm{HN}$ and $\mathrm{HH}$ groups showed lower 5- and 10-year survivals $(62.0 \%$ and $32.3 \%$, respectively, for the $\mathrm{HN}$ group and $50.7 \%$ and $29.0 \%$, respectively, for the $\mathrm{HH}$ group) than did patients in the $\mathrm{N}$ group $(91.7 \%$ and $82.8 \%: P<.0001)$.

Figure 3 shows survival curves according to the CEA group and the histologic type. Survivals of the HN group
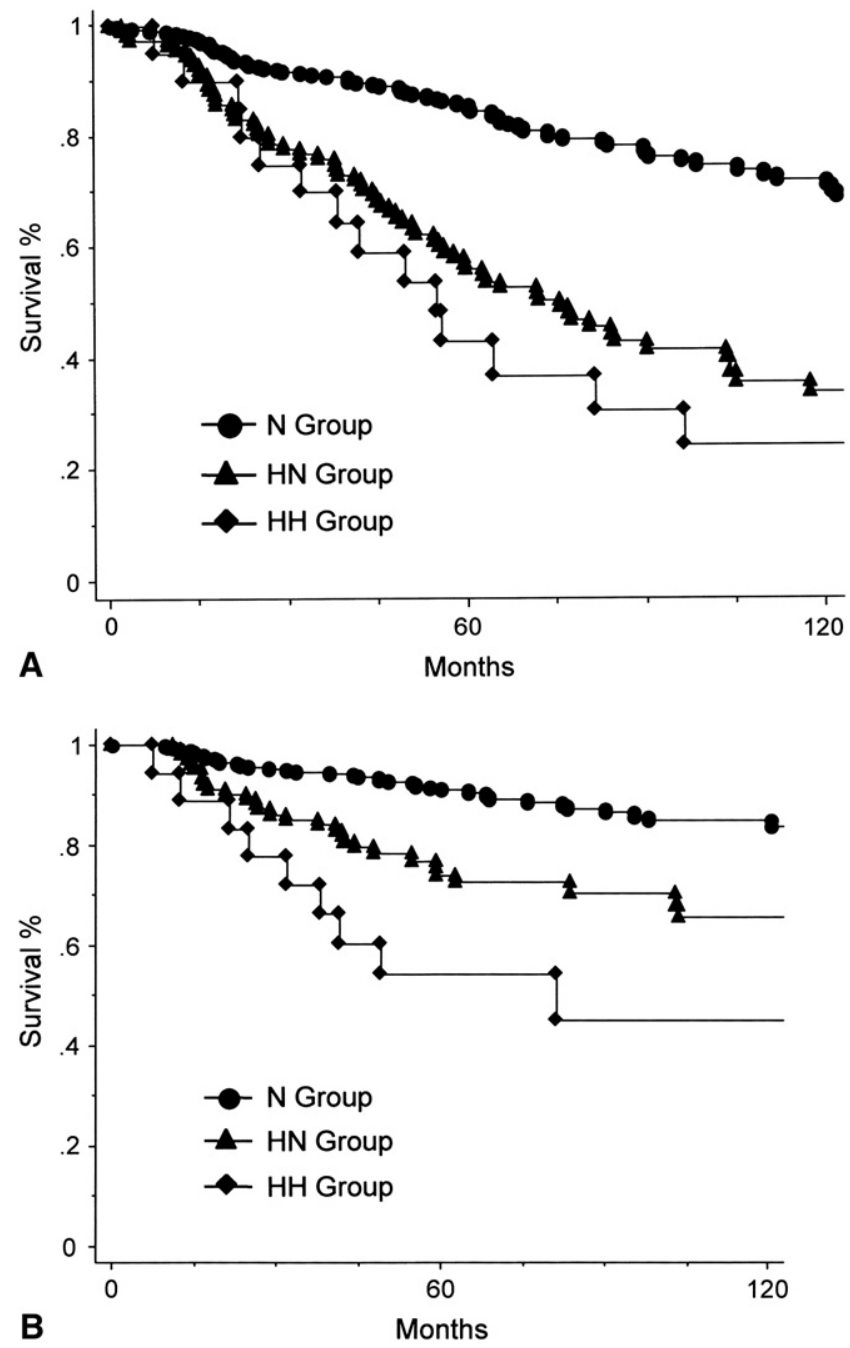

Figure 1. Survival curves (A) and cancer-specific survival curves (B) of patients with pathologic stage I NSCLC according to the CEA groups.

were significantly lower than those of the $\mathrm{N}$ group for both the adenocarcinoma and non-adenocarcinoma histologic types. The 5 -year survival was $46.3 \%$ for the HN group and $73.5 \%$ for the $\mathrm{N}$ group $(P=.0021)$ in patients with non-adenocarcinoma histology.

Multivariate analysis revealed that greater age, non-adenocarcinoma histology, pleural invasion, and the CEA HN and $\mathrm{HH}$ groups were independent prognostic factors (Table 2).

Figure 4 shows survival curves according to the number of positive prognostic factors, which include histologic type, VPI, and preoperative CEA value. We selected these prognostic factors on the basis of the results of multivariate analysis. However, age was removed because older patients were not considered suitable candidates for adjuvant chemotherapy. The 5-year survival was low (47.2\%) for patients with 

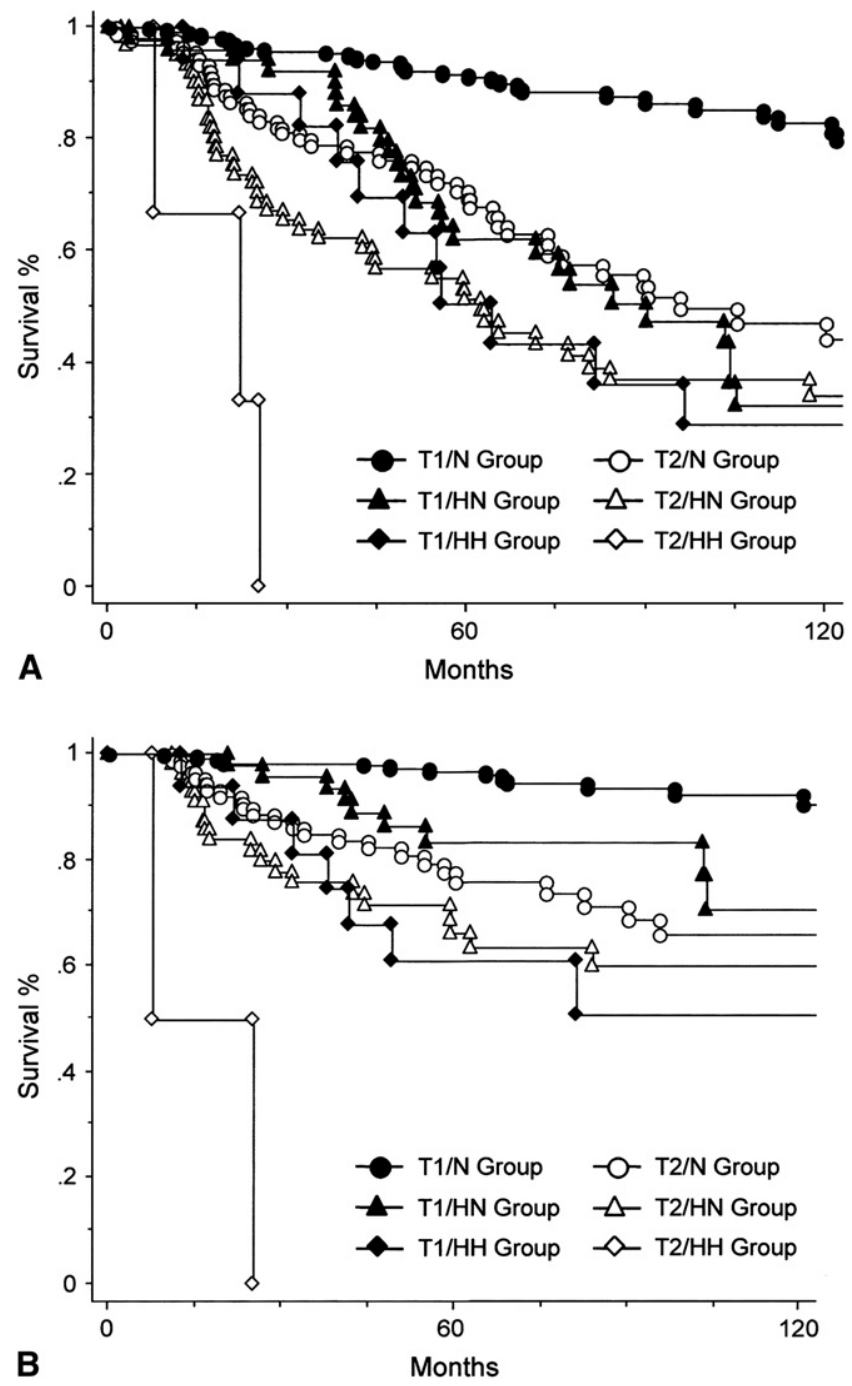

Figure 2. Survival curves (A) and cancer-specific survival curves (B) of patients with pathologic stage I NSCLC according to the CEA groups and pathologic $T$ factor.

2 or more positive prognostic factors. These patients made up $23 \%$ of all patients with stage I NSCLC.

\section{Discussion}

It is important to identify a subgroup of patients with pathologic stage I NSCLC who have a poor prognosis and may thus benefit from adjuvant chemotherapy. In general, available independent prognostic factors for this group of patients include VPI, ${ }^{9,10,14,15}$ BVI, ${ }^{9,10,14}$ lymphatic vessel invasion, ${ }^{14}$ pathologic T factor, ${ }^{9,15}$ tumor differentiation, ${ }^{10}$ and preoperative or postoperative serum tumor markers. ${ }^{5,6}$ Shimizu and colleagues $^{14}$ analyzed 1074 patients with pathologic T1 or T2 NSCLC, including 780 patients with pathologic stage I NSCLC, and found that age, sex, VPI, BVI, and lymphatic invasion were independent prognostic factors. Harpole and

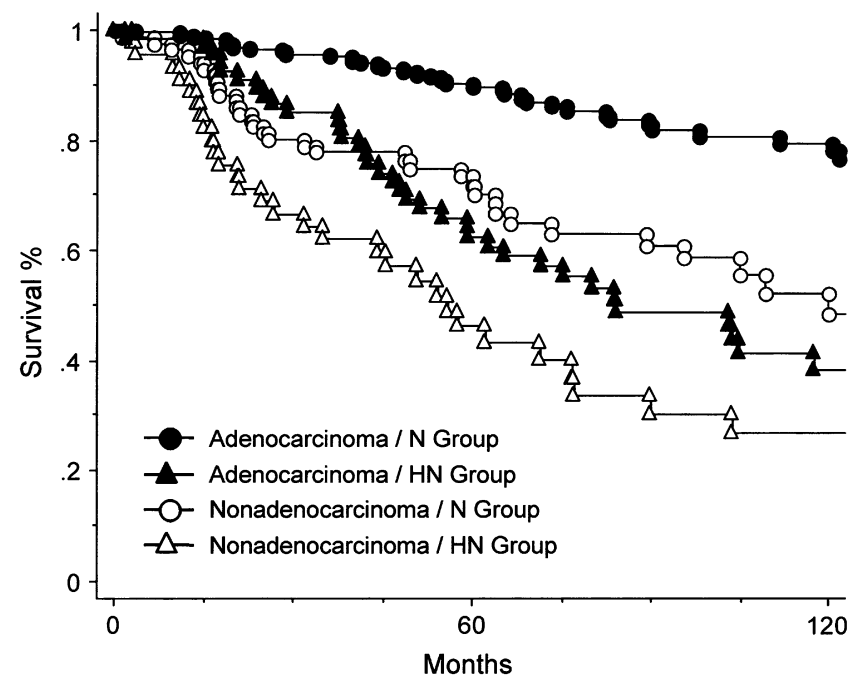

Figure 3. Survival curves of patients with pathologic stage I NSCLC according to the CEA group, excluding the HH group, and histologic type.

colleagues ${ }^{9}$ investigated 271 patients with pathologic stage I NSCLC and showed that BVI, VPI, and pathologic T factor were independent histopathologic prognostic factors and that angiogenesis, p53, and erbB-2 were independent molecular prognostic factors. Ichinose and colleagues ${ }^{10}$ also demonstrated that VPI, BVI, and tumor differentiation were independent prognostic factors. On the basis of these results, VPI and BVI have been established as independent pathologic prognostic factors for poor survival for patients with pathologic stage I NSCLC.

Tumor markers also have been investigated as prognostic factors because they are simple to measure and can clearly and consistently be judged as normal or abnormal in different institutions if a cutoff value is set. Among these tumor markers, CEA has been demonstrated to be an independent prognostic factor for patients with clinical stage I NSCLC. Okada and colleagues ${ }^{5}$ analyzed 1000 patients with clinical stage I NSCLC and found that the preoperative serum CEA level was an independent prognostic factor. Sawabata and colleagues ${ }^{6}$ reached the same conclusion after studying 273 patients with clinical stage I disease. However, neither study included established pathologic prognostic factors, such as VPI and BVI, in the multivariate analysis. In the present study, we adjusted for these prognostic factors, as well as for lymphatic invasion, histologic type, and smoking history, in the multivariate analysis and found that CEA is an independent prognostic factor.

The prognosis of the $\mathrm{HH}$ group has been reported to be poorer than that of the HN group by Okada and colleagues ${ }^{5}$ and Sawabata and colleagues. ${ }^{6}$ The present study also found that this subgroup had the poorest survival. Persistently high CEA levels after surgery may be related to occult residual 
TABLE 2. Multivariate analysis of overall survival

\begin{tabular}{|c|c|c|c|}
\hline Variable & Hazard ratio & $95 \% \mathrm{Cl}^{*}$ & $P$ value \\
\hline \multicolumn{4}{|l|}{ Age } \\
\hline$<67$ y & 1 & Reference & - \\
\hline$\geq 67 y$ & 2.909 & $2.016-4.198$ & $<.0001$ \\
\hline \multicolumn{4}{|l|}{ Sex } \\
\hline Female & 1 & Reference & - \\
\hline Male & 1.110 & $0.666-1.848$ & .6891 \\
\hline \multicolumn{4}{|l|}{ Histology } \\
\hline Adenocarcinoma & 1 & Reference & - \\
\hline Non-adenocarcinoma & 1.652 & $1.139-2.397$ & .0082 \\
\hline \multicolumn{4}{|l|}{ Smoking } \\
\hline Never & 1 & Reference & - \\
\hline Ever & 1.274 & $0.725-2.238$ & .4003 \\
\hline \multicolumn{4}{|l|}{ pT } \\
\hline $\mathrm{T} 1$ & 1 & Reference & - \\
\hline $\mathrm{T} 2$ & 1.358 & $0.930-1.985$ & .1133 \\
\hline \multicolumn{4}{|l|}{ Lymphatic invasion } \\
\hline No & 1 & Reference & - \\
\hline Yes & 1.084 & $0.700-1.679$ & .7164 \\
\hline \multicolumn{4}{|l|}{ Vascular invasion } \\
\hline No & 1 & Reference & - \\
\hline Yes & 1.283 & $0.879-1.872$ & .1962 \\
\hline \multicolumn{4}{|l|}{ Pleural invasion } \\
\hline No & 1 & Reference & - \\
\hline Yes & 1.827 & $1.280-2.608$ & .0009 \\
\hline \multicolumn{4}{|l|}{ CEA } \\
\hline $\mathrm{N}$ & 1 & Reference & - \\
\hline $\mathrm{HN}$ & 1.922 & $1.364-2.707$ & .0002 \\
\hline $\mathrm{HH}$ & 2.478 & $1.364-4.500$ & .0029 \\
\hline
\end{tabular}

$\mathrm{Cl}$, Confidence interval; $C E A$, carcinoembryonic antigen.

disease. Although patients of the $\mathrm{HH}$ group are candidates for adjuvant chemotherapy, the group population was small and accounted for only $4.3 \%$ of patients with pathologic stage I NSCLC in the present study. On the other hand, if high preoperative CEA levels normalize after surgery in patients with n0 disease, they are likely due to the primary tumor itself. Why is CEA-producing lung cancer associated with a poor prognosis? CEA-producing lung cancer has been shown to be associated with squamous cell carcinoma, moderately to poorly differentiated adenocarcinoma, BVI, lymphatic vessel invasion, and VPI. All of these pathologic features have been reported to be poor prognostic factors, ${ }^{8-10,14-16}$ and many of them have a documented association with smoking history. ${ }^{15,17}$ Fujisawa and colleagues ${ }^{15}$ demonstrated the prognostic value of smoking history in patients with pathologic stage I NSCLC. They also found that smoking history is significantly associated with the male sex, squamous histologic type, greater age, and pT2. Suzuki and colleagues ${ }^{17}$ showed that smoking history is associated with moderately to poorly differentiated adenocarcinoma. We speculate that a proportion of CEA-producing lung cancers are related to lung cancer caused by smoking.

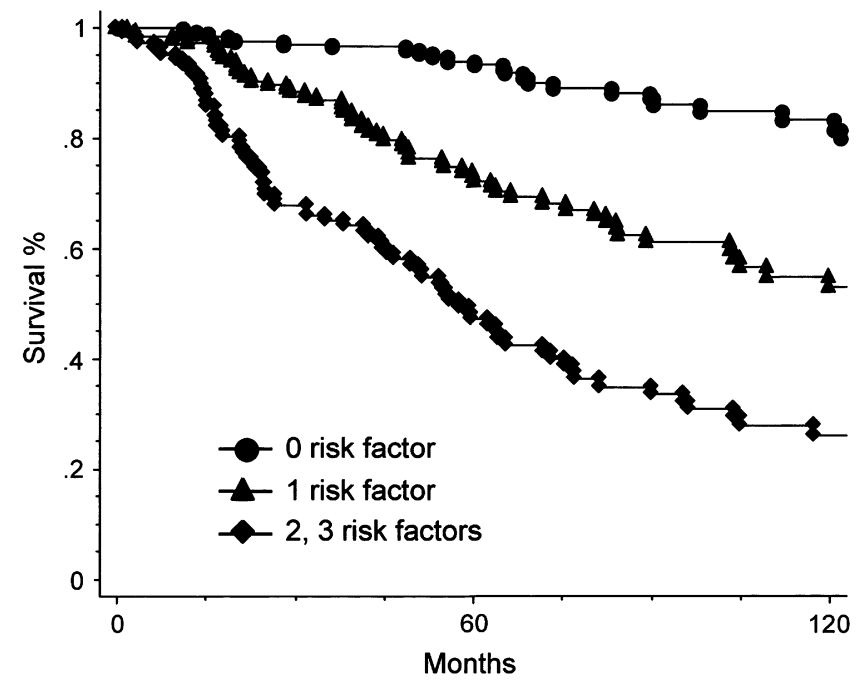

Figure 4. Survival curves of patients with pathologic stage I NSCLC according to the number of prognostic factors. Prognostic factors include histology, VPI, and preoperative CEA status.

In regard to the histologic type, we found that CEA levels were more often elevated in squamous cell carcinoma than in adenocarcinoma. Initially, CEA was investigated in colon adenocarcinoma and then mainly in gastrointestinal cancer. Therefore, some physicians may find our present results curious. However, similar results have been obtained by other studies. In the study reported by Okada and colleagues ${ }^{18}$ CEA was elevated in $9.0 \%$ (43/473) of patients with adenocarcinoma and in $13.4 \%(25 / 186)$ of patients with squamous cell carcinoma, ${ }^{16}$ and the survival of patients with elevated CEA levels was significantly lower than that of patients with normal CEA levels. Serum CEA levels have been shown to be elevated in patients with squamous cell carcinoma of the uterine cervix ${ }^{18}$ and esophagus. ${ }^{19}$ According to a study by Bae and colleagues, ${ }^{18}$ CEA levels were elevated in $30.2 \%$ in patients with stage IB2 to IIA squamous cell carcinoma of the uterine cervix, and the recurrence rate in patients with high CEA levels was $30.8 \%$, which was higher than that of patients with low CEA levels (6.7\%). In our study, the survival of the HN group was significantly lower than that of the $\mathrm{N}$ group in patients with non-adenocarcinoma histology. From these results, we conclude that CEA is a useful prognostic factor for all histologic types in patients with pathologic stage I NSCLC.

In this study, we found that greater age, non-adenocarcinoma histology, VPI, and CEA were poor independent prognostic factors for patients with pathologic stage I NSCLC. On the basis of these results, we propose that candidates for adjuvant chemotherapy be selected on the basis of poor prognosis identified with a combination of these factors other than greater age. Older patients are not generally considered 
candidates for adjuvant chemotherapy. We simply divided the patients into 3 groups according to the presence of these 3 prognostic factors. The 5-year survival of patients with 2 or more factors was only $47.2 \%$, and these patients accounted for $23 \%$ of all patients with stage I NSCLC. Consequently, these patients are thought to be good candidates for adjuvant chemotherapy.

\section{Conclusions}

CEA, VPI, and non-adenocarcinoma histology were found to be poor independent prognostic factors in patients with completely resected pathologic stage I NSCLC. Prospective studies are warranted to clarify the benefits of adjuvant chemotherapy for the subgroup with a poor prognosis identified on the basis of the 3 prognostic factors in patients with stage I NSCLC.

\section{References}

1. Winton T, Livingston R, Johnson D, Rigas J, Johnston M, Butts C, et al. Vinorelbine plus cisplatin vs. observation in resected non-small-cell lung cancer. N Engl J Med. 2005;352:2589-97.

2. Arriagada R, Bergman B, Dunant A, Le Chevalier T, Pignon JP, Vansteenkiste J. Cisplatin-based adjuvant chemotherapy in patients with completely resected non-small-cell lung cancer. $N$ Engl J Med. 2004;350:351-60.

3. Douillard JY, Rosell R, De Lena M, Carpagnano F, Ramlau R, Gonzales-Larriba JL, et al. Adjuvant vinorelbine plus cisplatin versus observation in patients with completely resected stage IB-IIIA non-small-cell lung cancer (Adjuvant Navelbine International Trialist Association [ANITA]): a randomised controlled trial. Lancet Oncol. 2006;7:719-27.

4. Potti A, Mukherjee S, Petersen R, Dressman HK, Bild A, Koontz J, et al. A genomic strategy to refine prognosis in early-stage non-small-cell lung cancer. N Engl J Med. 2006;355:570-80.

5. Okada M, Nishio W, Sakamoto T, Uchino K, Yuki T, Nakagawa A, et al. Prognostic significance of perioperative serum carcinoembryonic antigen in non-small cell lung cancer: analysis of 1,000 consecutive resections for clinical stage I disease. Ann Thorac Surg. 2004;78:216-21.

6. Sawabata N, Ohta M, Takeda S, Hirano H, Okumura Y, Asada H, et al. Serum carcinoembryonic antigen level in surgically resected clinical stage I patients with non-small cell lung cancer. Ann Thorac Surg. 2002;74:174-9.
7. Harpole DH Jr, Herndon JE 2nd, Wolfe WG, Iglehart JD, Marks JR. A prognostic model of recurrence and death in stage I non-small cell lung cancer utilizing presentation, histopathology, and oncoprotein expression. Cancer Res. 1995;55:51-6.

8. Macchiarini P, Fontanini G, Hardin MJ, Chuanchieh H, Bigini D, Vignati $\mathrm{S}$, et al. Blood vessel invasion by tumor cells predicts recurrence in completely resected T1 N0 M0 non-small-cell lung cancer. $J$ Thorac Cardiovasc Surg. 1993;106:80-9.

9. Harpole DH Jr, Richards WG, Herndon JE 2nd, Sugarbaker DJ. Angiogenesis and molecular biologic substaging in patients with stage I nonsmall cell lung cancer. Ann Thorac Surg. 1996;61:1470-6.

10. Ichinose Y, Yano T, Asoh H, Yokoyama H, Yoshino I, Katsuda Y. Prognostic factors obtained by a pathologic examination in completely resected non-small-cell lung cancer. An analysis in each pathologic stage. J Thorac Cardiovasc Surg. 1995;110:601-5.

11. Takamochi K, Nagai K, Suzuki K, Yoshida J, Ohde Y, Nishiwaki Y. Clinical predictors of $\mathrm{N} 2$ disease in non-small cell lung cancer. Chest. 2000;117:1577-82.

12. Mountain CF. Revisions in the International System for Staging Lung Cancer. Chest. 1997;111:1710-7.

13. World Health Organization. Histological Typing of Lung and Pleural Tumours. 3rd ed. Geneva: World Health Organization; 1999.

14. Shimizu K, Yoshida J, Nagai K, Nishimura M, Ishii G, Morishita Y, et al. Visceral pleural invasion is an invasive and aggressive indicator of non-small cell lung cancer. J Thorac Cardiovasc Surg. 2005;130: 160-5.

15. Fujisawa T, Iizasa T, Saitoh Y, Sekine Y, Motohashi S, Yasukawa T, et al. Smoking before surgery predicts poor long-term survival in patients with stage I non-small-cell lung carcinomas. J Clin Oncol. 1999; 17:2086-91

16. Okada M, Nishio W, Sakamoto T, Uchino K, Yuki T, Nakagawa A, et al. Effect of histologic type and smoking status on interpretation of serum carcinoembryonic antigen value in non-small cell lung carcinoma. Ann Thorac Surg. 2004;78:1004-10.

17. Suzuki T, Sobue T, Fujimoto I, Doi O, Tateishi R. Association of adenocarcinoma of the lung with cigarette smoking by grade of differentiation and subtype. Cancer Res. 1990;50:444-7.

18. Bae SN, Namkoong SE, Jung JK, Kim CJ, Park JS, Kim JW, et al. Prognostic significance of pretreatment squamous cell carcinoma antigen and carcinoembryonic antigen in squamous cell carcinoma of the uterine cervix. Gynecol Oncol. 1997;64:418-24.

19. Kosugi S, Nishimaki T, Kanda T, Nakagawa S, Ohashi M, Hatakeyama K. Clinical significance of serum carcinoembryonic antigen, carbohydrate antigen 19-9, and squamous cell carcinoma antigen levels in esophageal cancer patients. World J Surg. 2004;28:680-5. 